www.jmscr.igmpublication.org Impact Factor 5.244

Index Copernicus Value: 5.88 ISSN (e)-2347-176x ISSN (p) 2455-0450 crossref DOI:_http://dx.doi.org/10.18535/jmscr/v4i6.18

\title{
Cytomorphological Patterns and Histopathological Correlation of Breast Lesions in a Tertiary Care Centre- A Two Year Retrospective Study (Original Article)
}

\author{
Authors \\ Rajnish Kalra ${ }^{1}$, Jyoti Sharma ${ }^{2}$, Neha Yadav ${ }^{3}$, Sonu Kalyan ${ }^{4}$, \\ Sunita Singh $^{5}$, Sumiti Gupta ${ }^{6}$ \\ ${ }^{1,6}$ Professor, Dept of Pathology, Pt BDS PGIMS, Rohtak, Haryana \\ ${ }^{2}$ Senior Resident, Pt BDS PGIMS, Rohtak, Haryana \\ ${ }^{3,4}$ Resident, Pt BDS PGIMS, Rohtak, Haryana \\ ${ }^{5}$ Senior Professor, Pt BDS PGIMS, Rohtak, Haryana \\ Email: ${ }^{1}$ kalrarajnish64@gmail.com, ${ }_{5}^{2}$ drjyoti1212@yahoo.in, ${ }_{5}^{4}$ srkmlk967@gmail.com, \\ ${ }^{5}$ sunita62@gmail.com, 6 guptasumiti30@yahoo.com \\ Corresponding Author

\section{Neha Yadav} \\ Department of Pathology, Pt. B.D. Sharma, PGIMS Rohtak, Haryana 124001 (India) \\ Email: yadavneha01712@gmail.com
}

\begin{abstract}
Background: Breast lesions including breast cancer represent a major public health issue worldwide. Fine needle aspiration cytology (FNAC) is established as most sensitive, specific, accurate, safe and cost effective for diagnosing lesions of breast preoperatively and avoiding unnecessary surgical interventions like diagnostic excision or incisional biopsy. The aim of this study is to determine the most common breast lesions diagnosed by FNAC and its histopathological correlation over a two year period.

Material and Methods: A total of 1084 cases with palpable breast lesions were subjected to FNAC over a period of two year. A provisional clinical diagnosis was made in each case at the outset. Routine investigations like DLC, TLC, ESR and special investigations like Mammography were done. Air dried and wet fixed (95\% alcohol) smears were prepared for Leishman and Papanicolaou or Hematoxylin and Eosin stain respectively. Special stains were used like Ziehl-Neelsen stain and Periodic Acid Schiff (PAS) stain wherever necessary. Diagnosis was made on the basis of cytomorphological features of the lesion. Out of 1084 patients, only 100 patients who were diagnosed with malignancy on FNAC were reviewed with biopsies or postoperatively in our department and were confirmed histopathologically.

Results: The study shows that out of 1084 cases, total number of benign lesions were $73.8 \%$, malignant lesions were $22.1 \%$, equivocal cases were $7.5 \%$, cases for suspicious of malignancy were $2.9 \%$ and $1.75 \%$ cases were inadequate. Maximum number of cases reported as breast carcinoma were seen in age group of 41-50 years (31.3\%) and second highest number were seen in 51-60 years (26.3\%) with male (88 cases) to female (977 cases) ratio of 0.09:1. Among 800 benign lesions, fibroadenoma was the most significant lesion observed constituting 44.9\%, second most common lesion encountered was benign mammary lesion constituting $18.9 \%$ followed by inflamed/ acute cystic lesion, (47.5\%). Gynaecomastia constituting (35.4\%),
\end{abstract}


granulomatous lesion (4.1\%), acute mastitis (3.33\%), breast abscess (1.25\%). On the other hand among 240 malignant lesions, majority of were ductal carcinoma (238 cases), 1 cases was of mucinous carcinoma, 1 case was of medullary carcinoma.

Conclusion: This study supports the usefulness of cytomorphological diagnostic techniques in the workout of breast lesions, confirms the predominance of breast lesions in the young and increased malignancy in the $4^{\text {th }}$ decade or above. FNAC is a valuable diagnostic tool in conjunction with radiological and clinical data of palpable breast lesions.

Keywords: Breast lesions, FNAC, Histopathology

\section{Introduction}

With growing awareness in the general population, a lady with a breast lump is one of the commonest presentation in outpatient department. Diseases of breast mainly present as palpable masses, nipple discharge, or abnormalities on imaging studies. However, most of these lesions are benign with the exception of carcinoma of breast, which is the leading cause of morbidity and mortality. ${ }^{1}$ Breast cancer is the most common malignant tumor in women globally. In the USA, approximately 232,670 new cases were diagnosed and 40,000 deaths recorded in 2014, contributing to a significant proportion of health care spending. ${ }^{2}$ In India it is the second most common cancer after cancer cervix. Currently 75,000 new cases of breast cancer are detected in India yearly. ${ }^{3}$ Cytology can explore breast lesions in three distinct ways; Fine Needle Aspiration Cytology (FNAC), scraping of skin (SS), and smearing of nipple discharge (ND). FNAC of breast lump is an important part of triple assessment (the other two are clinical examination and mammography) of palpable breast lump. It is an accurate, rapid, easy to perform, cost effective procedure for diagnosing non-neoplastic lesions of breast preoperatively and avoiding unnecessary surgical interventions like diagnostic excision or incisional biopsy. ${ }^{4}$ The objective of present study was to determine the cytomorphological patterns of breast lesions which were diagnosed by FNAC and correlated with histopathologically.

\section{Material and Methods}

This was a retrospective study done over a period of two years from January 2013 to December 2014. The study comprised of total 1084 patients came in outpatient department and referred to department of pathology for FNAC. A provisional clinical diagnosis was made in each case at the outset. Routine investigations like DLC, TLC, ESR and special investigations like Mammography were done. After obtaining detailed history and physical examination of breast lump; FNAC was performed in each case using a $23 \mathrm{G}$ needle. An average of 2-3 passes were made and 4 slides were prepared. One slide was air dried and was stained by Leishman or May-Grunwald Giemsa stain whereas other was stained by Papanicolaou stain. One slide was left unstained for performing special stains like ZiehlNeelsen stain and Periodic Acid Schiff (PAS) stain wherever necessary.

\section{Observation}

The present study was carried out over a period of two year from January 2013 to December 2014. FNAC was performed on 1084 patients referred to pathology department with compliant of breast lump out of which 19 cases were excluded from the study due to inadequate aspirate. Out of the 1084 patients, $8.12 \%(\mathrm{n}=88)$ patients were males with $90.1 \%$ $(\mathrm{n}=977)$ cases being females leading to a M: F ratio of 0.09:1 (Figure 1) 
Figure 1:

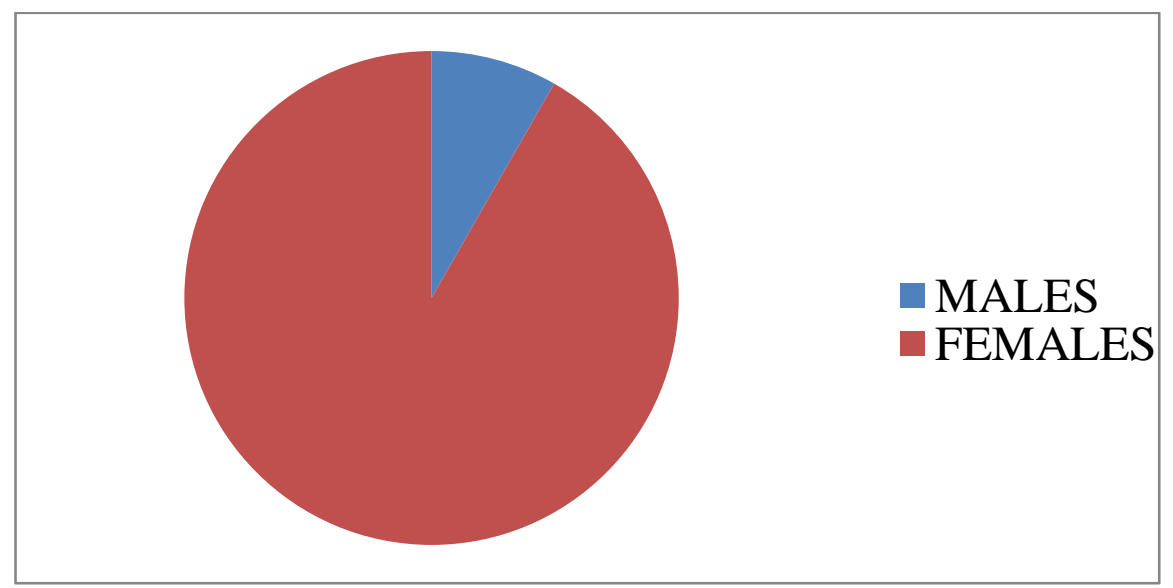

There is slightly more number of cases observed in year $2014(\mathrm{n}=125)$ as compared to year $2013(\mathrm{n}=115)$ depicted in figure 2.

Figure 2:

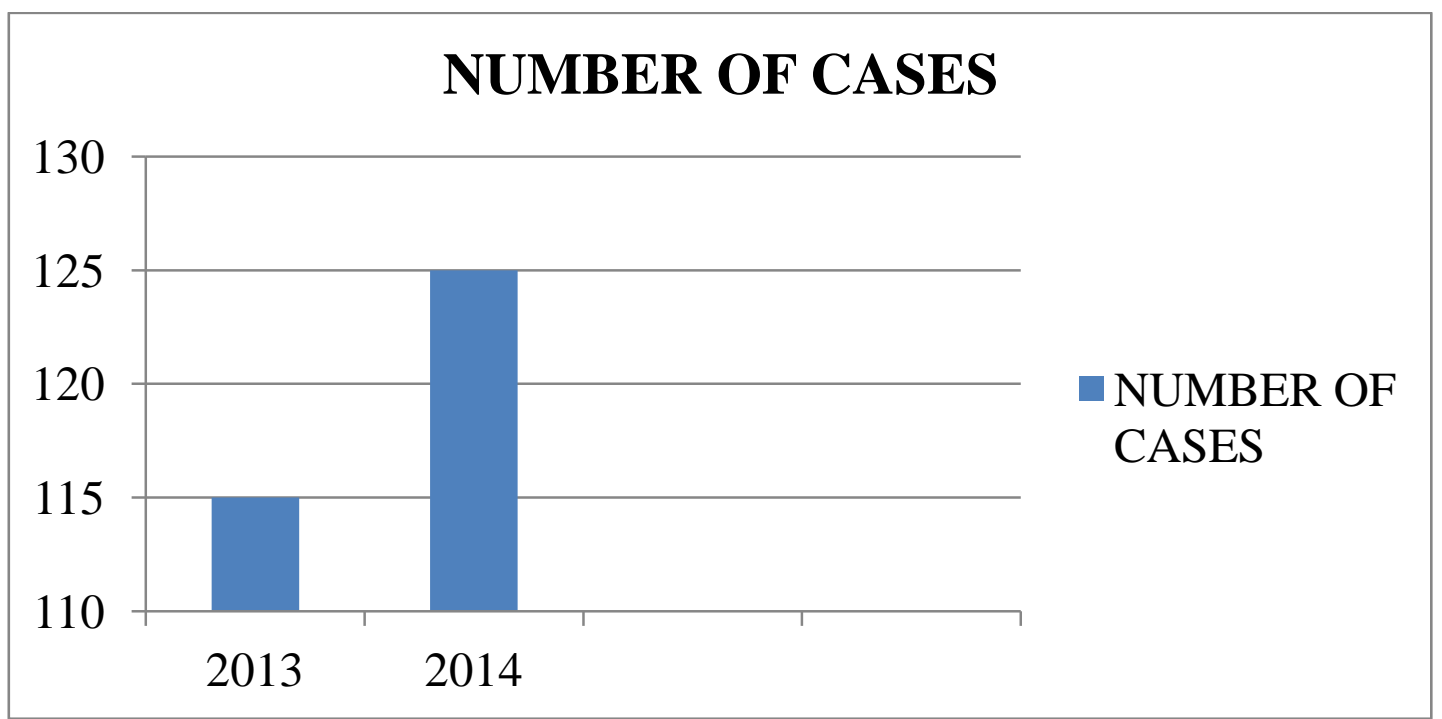

Maximum number of non-neoplastic cases, i.e., 30.4\% ( $n=330)$ were reported in age group of 21-30 years; whereas second highest number of cases were seen in age group of 31-40 years (22.4\%), (Table 1)

Table 1: Age wise distribution of Non-Neoplastic lesion of breast:

\begin{tabular}{|l|l|l|}
\hline $\begin{array}{l}\text { Age group } \\
(\text { years })\end{array}$ & No. of patients & $\begin{array}{l}\text { Percentage } \\
(\%)\end{array}$ \\
\hline $0-10$ & 01 & 0.09 \\
\hline $11-20$ & 137 & 12.6 \\
\hline $21-30$ & 330 & 30.4 \\
\hline $31-40$ & 243 & 22.4 \\
\hline $41-50$ & 174 & 16.0 \\
\hline $51-60$ & 129 & 11.9 \\
\hline $61-70$ & 49 & 4.5 \\
\hline $71-80$ & 19 & 1.75 \\
\hline $81-90$ & 01 & 0.09 \\
\hline $91-100$ & 01 & 0.09 \\
\hline Total & 1084 & 100 \\
\hline
\end{tabular}

However, maximum number of cases reported as breast carcinoma were seen in age group of 41-50 years i.e.31.3\% ( $n=75$ out of total 240 breast carcinoma cases) and second highest number were seen in 51-60 years (26.3\%), Table 2. The least number of both benign and malignant lesions i.e., $0.09 \%(n=1)$ were seen in first and eighth decade of life. 
Table 2: Age wise distribution of Neoplastic lesion of breast:

\begin{tabular}{|l|c|c|}
\hline $\begin{array}{l}\text { Age group } \\
\text { (years) }\end{array}$ & $\begin{array}{c}\text { No of } \\
\text { patients }\end{array}$ & Percentage(\%) \\
\hline $0-10$ & - & - \\
\hline $11-20$ & 02 & 0.8 \\
\hline $21-30$ & 13 & 5.4 \\
\hline $31-40$ & 47 & 19.6 \\
\hline $41-50$ & 75 & 31.6 \\
\hline $51-60$ & 63 & 26.6 \\
\hline $61-70$ & 31 & 12.9 \\
\hline $71-80$ & 08 & 3.33 \\
\hline $81-90$ & 01 & 0.4 \\
\hline $91-100$ & - & - \\
\hline Total & 240 & 100 \\
\hline
\end{tabular}

The study showed that out of 1084 cases, total number of benign lesions were $73.8 \% \quad(n=800)$, malignant lesions were $22.1 \%(n=240)$, equivocal cases were $18(7.5 \%)$, cases for suspicious of malignancy were $2.9 \%(n=7)$ and 19 cases were inadequate (figure 3). FNAC was unsatisfactory in $1.75 \% \quad(n=19)$ cases whereas diagnosis was offered in $98.2 \%(n=1065)$ cases leading to a high sensitivity of the technique.

\section{Figure 3:}

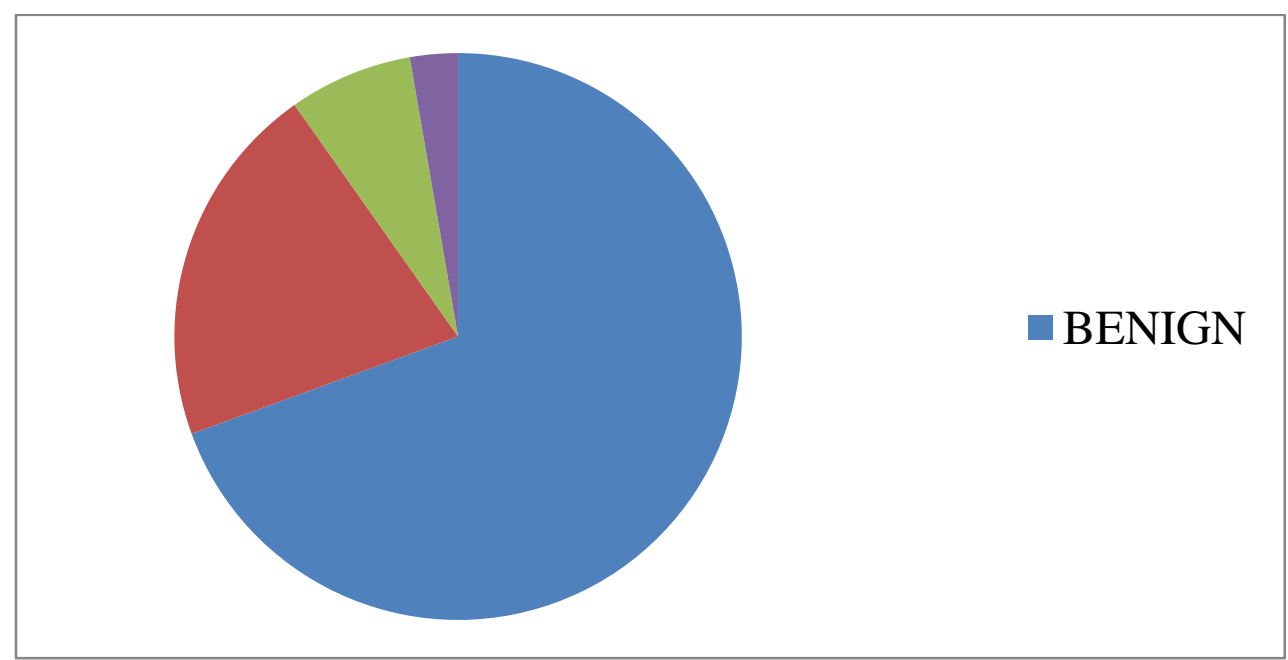

The cytomorphological spectrum of various benign breast lesion encountered in the present study shows that out of total 800 benign lesions, fibroadenoma was the most significant lesion observed constituting $44.9 \%(n=367)$. (Table 3 )

The second most common lesion encountered was benign mammary lesion constituting $18.9 \%$ $(\mathrm{n}=156)$; followed by inflamed/ acute cystic lesion, 114 cases (47.5\%). Gynaecomastia constituting 85 cases (35.4\%), granulomatous lesion; 10 cases $(4.1 \%)$, acute mastitis; 8 cases (3.33\%), breast abscess; 3 cases $(1.25 \%)$,

(Figure 4)
Table 3:

Cytomorphological spectrum of various benign lesions:

\begin{tabular}{|l|l|l|}
\hline Cytological Diagnosis & $\begin{array}{l}\text { No. of } \\
\text { Cases }\end{array}$ & $\begin{array}{l}\text { Percentage } \\
\%\end{array}$ \\
\hline Benign mammary lesion & 156 & 14.4 \\
\hline $\begin{array}{l}\text { Benign mammary } \\
\text { proliferative lesion }\end{array}$ & 121 & 11.2 \\
\hline Fibroadenoma & 246 & 22.7 \\
\hline Phyllodes tumor & 02 & 0.2 \\
\hline Fibrocystic disease & 13 & 1.2 \\
\hline Gynaecomastia & 85 & 7.8 \\
\hline Acute cystic lesions & 114 & 10.5 \\
\hline Acute mastitis & 08 & 0.74 \\
\hline Breast abscess & 03 & 0.28 \\
\hline Granulomatous lesion & 10 & 0.9 \\
\hline Necrotising & 08 & 0.74 \\
\hline
\end{tabular}




\begin{tabular}{|l|l|l|}
\hline granulomatous lesion & & \\
\hline Duct ectasia & 01 & 0.09 \\
\hline Duct papilloma & 02 & 0.18 \\
\hline Papillary lesions & 02 & 0.18 \\
\hline Galactocoele & 09 & 0.83 \\
\hline Organising inflammation & 02 & 0.18 \\
\hline Fat necrosis & 05 & 0.46 \\
\hline Epidermal cyst & 03 & 0.28 \\
\hline Lipoma & 09 & 0.83 \\
\hline Lymphoma & 01 & 0.09 \\
\hline Total & 800 & 100 \\
\hline
\end{tabular}

Table 4: Cytomorphological spectrum of various malignant lesions:

\begin{tabular}{|l|l|l|}
\hline $\begin{array}{l}\text { Cytological } \\
\text { Diagnosis }\end{array}$ & $\begin{array}{l}\text { No. of } \\
\text { Cases }\end{array}$ & Percentage \% \\
\hline Ductal carcinoma & 238 & 99.1 \\
\hline $\begin{array}{l}\text { Medullary } \\
\text { carcinoma }\end{array}$ & 01 & 0.42 \\
\hline $\begin{array}{l}\text { Mucinous } \\
\text { carcinoma }\end{array}$ & 01 & 0.42 \\
\hline Total & 240 & 100 \\
\hline
\end{tabular}

On the other hand, the cytomorphological spectrum of various malignant lesions encountered in the study shows (Table 4) that out of 240 cases majority of were ductal carcinoma (238 cases), 1 cases was of mucinous carcinoma, 1 case was of medullary carcinoma. Out of 1084 patients, only 100 patients who were diagnosed with malignancy on FNAC were reviewed with biopsies or postoperatively in our department and were confirmed histopathologically. (Figure 5)

\section{Figure 4:}
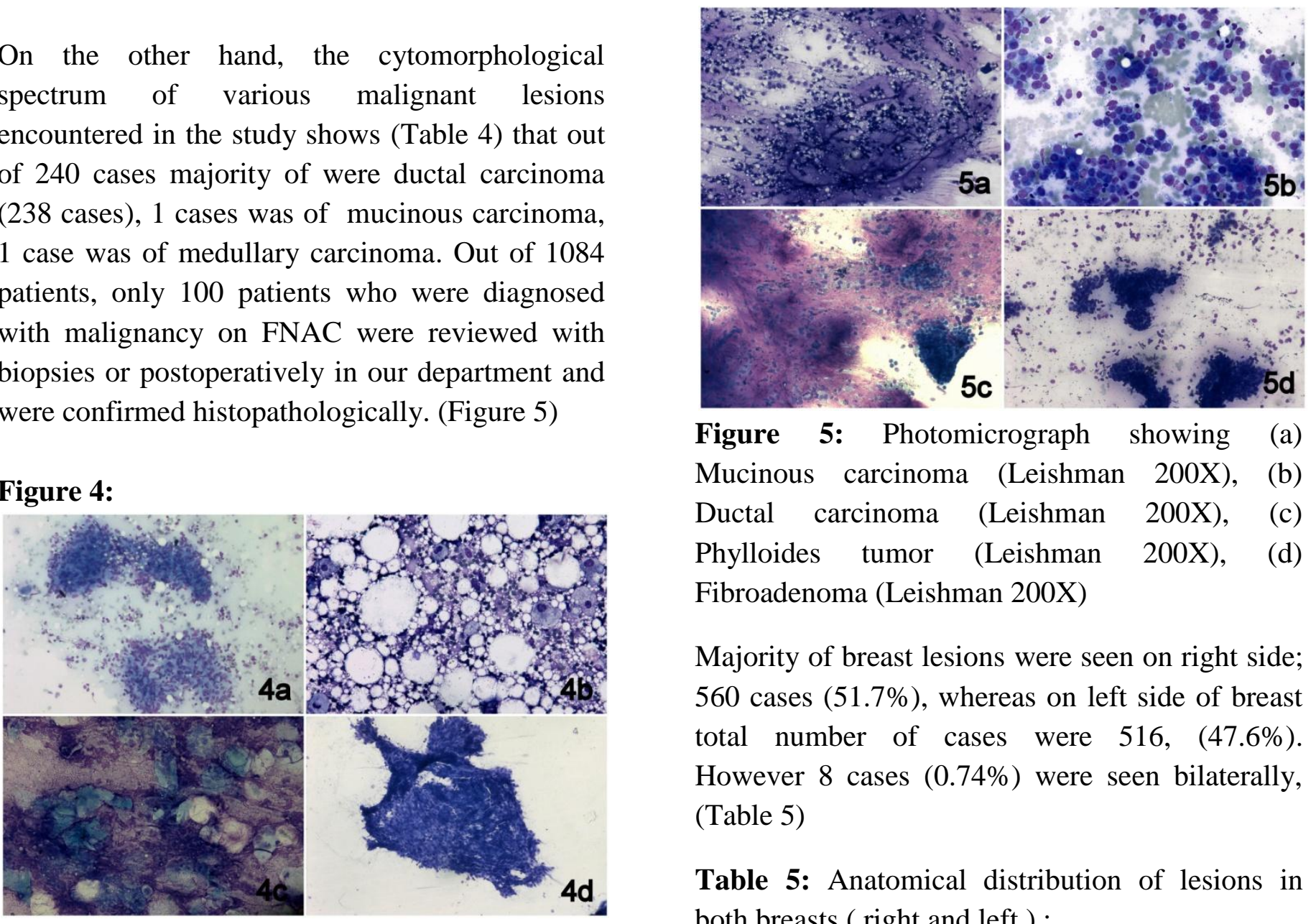

Figure 5: Photomicrograph showing (a)

Mucinous carcinoma (Leishman 200X), (b)

Ductal carcinoma (Leishman 200X), (c)

Phylloides tumor (Leishman 200X), (d)

Fibroadenoma (Leishman 200X)

Majority of breast lesions were seen on right side; 560 cases $(51.7 \%)$, whereas on left side of breast total number of cases were 516, (47.6\%). However 8 cases $(0.74 \%)$ were seen bilaterally, (Table 5)

Table 5: Anatomical distribution of lesions in both breasts ( right and left ) :

Figure 4: Photomicrograph showing (a) Granulomatous mastitis (Leishman 200X), (b) Fat necrosis (Leishman 200X), (c) Epidermal cyst (Leishman 200X), (d) Gynaecomastia (Leishman $200 \mathrm{X}$ )

\begin{tabular}{|l|l|l|}
\hline Side & Cases & Percentage \% \\
\hline Right & 560 & 51.7 \\
\hline Left & 516 & 47.6 \\
\hline Bilateral & 08 & 0.74 \\
\hline Total & 1084 & 100 \\
\hline
\end{tabular}

\section{Discussion}

As most of the non-neoplastic lesions of breast presenting as breast lump appear neoplastic, making clinical diagnosis difficult. FNAC is an valuable diagnostic tool for preoperative diagnosis 
so as to avoid unnecessary surgery and to give accurate diagnosis. In the present study, age of the patients with benign breast lesions ranged from 15-75 years of age group; similar age group i.e. 17-72 years was also observed by chandawale et al. ${ }^{5}$ Majority $(88 \%)$ of patients were belonged to premenopausal age and the commonest age group was 21-30 year (38\%) followed by 31-40 year (30.4\%). However, malignant lesions were predominantly seen at $4^{\text {th }}$ and $5^{\text {th }}$ decade of life which were in concordance with previous study of Jack et al; 2012. ${ }^{6}$ Benign lesions were much more common comprising $73.8 \%$ cases in contrast to $22.1 \%$ cases diagnosed as malignant. Similar findings suggested by Dennsion $\mathrm{G}$ et al; found that out of 143 cases, $73.4 \%$ cases were benign compared to $26.6 \%$ malignant cases. ${ }^{7}$ Among 800 benign breast lesions, fibroadenoma was the most significant lesion observed constituting 44.9\% $(n=367)$. The second most common lesion encountered was benign mammary lesion constituting $18.9 \% \quad(\mathrm{n}=156)$; followed by inflamed/ acute cystic lesion, 114 cases (47.5\%); Gynaecomastia constituting 85 cases (35.4\%). Similarly other studies also reported fibroadenoma as the most commonly encounterd lesions; $45.91 \%$ by Likhar et al in $2013,{ }^{8} 46.27 \%$ by Chandawale et $\mathrm{al}^{5}$ and $46.27 \%$ by Sankaye et al in 2014. ${ }^{9}$ We had 240 malignant cases and 7 cases as suspicious of malignancy. Majority (99\%) of cases were ductal carcinoma (238 cases), 1 cases was of mucinous carcinoma, 1 case was found as medullary carcinoma on FNAC and later biopsy were performed as advised. 100 patients underwent surgery and cases referred to us in the form of trucut biopsy, lumpectomy or mastectomy. Histopathological representative microsections examined and the diagnosis of ductal carcinoma was confirmed in majority of them. One case was reported as ductal carcinoma with mucinous change and one was confirmed as medullary carcinoma of breast. Among 7 suspicious cases of malignancy, only 5 patients came to follow up; trucut biopsy was performed and sent to us; diagnosis of ductal carcinoma made in 3 of them while 2 showed atypical ductal hyperplasia. Ductal carcinoma is the commonest type of breast carcinoma seen worldwide, as well as in our study corroborates with Harirchi I et al ${ }^{10}$ and Singh et al. ${ }^{11}$

\section{Conclusion}

This study supports the usefulness of cytomorphological diagnostic techniques in the workout of breast lesions, confirms the predominance of breast lesions in the young and increased malignancy in the $4^{\text {th }}$ decade or above. FNAC is a valuable diagnostic tool in conjunction with radiological and clinical data of palpable breast lesions. FNAC is accepted as most sensitive, specific, accurate, safe and cost effective for diagnosing lesions of breast preoperatively and avoiding unnecessary surgical interventions like diagnostic excision or incisional biopsy.

\section{References}

1. Muddegowda PH, Lingegowda JB, Kurpad RK, Konapur PG, Shivarudrappa AS, Subramaniam PM. The value of systematic pattern analysis in FNAC of breast lesions:225 cases with cytohistologic correlation. J Cytol. 2011;28:13-19.

2. Siegel R, Ma J, Zou Z, Jemal A. Cancer statistics. Cancer J Clin. 2014;64:9-29.

3. Chopra R. The Indian scene. J Clin Oncol. 2001;19:106-11.

4. Strawbridge TG, Basset AA. Role of cytology in management of lesions of the breast. Surg Gynaecol Obstet. 1981; 152(1):1-7.

5. Chandawale SS, Gupta K, Dharwadkar AA, Pal S, Buch AC, Mishra N. Patterns of palpable breast lesions on fine needle aspiration: A retrospective analysis of 902 cases. J Midlife Health. 2014;5:186-91.

6. Jack RH, Davies EA, Moller H. Breast cancer and age in black and white women in South East England. Int $\mathbf{J}$ Cancer. 2012;130:1227-29. 
7. Dennison G, Anand R, Makar SH. A prospective study of the use of fine needle aspiration cytology and core biopsy in the diagnosis of breast cancer. The Breast Journal. 2003;9:491-93.

8. Likhar KS Fatima A, Hazari RA, Gupta SG, Shukla U. Diagnostic role of FNAC in breast lesions. IJRRMS. 2013;3:12-14.

9. Sankye SB, Dongre SD. Cytological study of palpable breast lumps presenting in an Indian rural setup. Indian J Med Paediatr Oncol. 2014;35:159-64.

10. Harirchi I, Ebrahim M, Zamani N.Breast cancer in Iran: a review of 903 case records. Public Health. 2000;114:143-45.

11. Singh A, Haritwal A, Murali BM. Patterns of breast lumps and diagnostic accuracy of fine needle aspiration cytology; a hospital based study from Pondicherry, India. Internet J Pathol. 2011;11(2). 